\title{
Propuestas de creación de Realidad Aumentada en el ámbito de la historia del arte: casos prácticos en el entorno histórico-artístico malagueño
}

Proposals for the creation of Augmented Reality in the field of art history: case studies in the historical-artistic environment of Malaga

\author{
Sandra Medina Bueno \\ ${ }^{1}$ Departamento de Historia del Arte, Universidad de Málaga, España (sandra_medina93@hotmail.com)
}

Recibido el 12 de mayo de 2017; revisado el 13 de junio de 2017; aceptado el 17 de junio de 2017; publicado el 01 de juilo de 2017

RESUMEN: A lo largo de este recorrido se pretende demostrar la relevancia que están teniendo las nuevas tecnologías en todos los campos por los que se expande el mundo del arte (museos, patrimonio, aulas, etc.), así como los nuevos paradigmas que están surgiendo ante las nuevas formas de realizarlo. Entre ellas, la realidad aumentada está apareciendo como una nueva herramienta a través de la cual se están experimentando nuevas fórmulas dentro del campo artístico. De este modo, nos centraremos en la ciudad de Málaga con la finalidad de elaborar diferentes propuestas prácticas que aborden estos nuevos paradigmas que están aconteciendo en nuestro entorno más cercano.

PALABRAS CLAVE: Realidad Aumentada, Málaga, Museum Jorge Rando, código QR, nuevas tecnologías.

\begin{abstract}
Along this route is intended to demonstrate the importance that new technologies are having on all fields that expands all over the world of art (museums, heritage, classrooms, etc.), as well as the new paradigms are emerging in new forms of doing it. Among them, augmented reality is emerging as a new tool through which you are experiencing new forms within the artistic field. In this way, we will focus on the city of Malaga in order to develop different practical proposals that address these new paradigms that are happening in our immediate environment.
\end{abstract}

KEYWORDS: Augmented Reality, Malaga, Museum Jorge Rando, QR code, new technologies. 


\title{
Renovarse o morir: aplicación de algunos casos prácticos de realidad aumentada en el entorno artístico malagueño
}

\author{
“La espiritualidad de la época que nos toca vivir nos condiciona a la \\ imposibilidad de definir la realidad [...]', Marcelo Martín.
}

En cuanto al significado de este término tan reciente, la profesora Bellido Gant define la realidad aumentada de la siguiente manera (2008: 44): “[... consiste en un conjunto de dispositivos que añaden información virtual a la información física ya existente y que no sustituye a la realidad física, sino que superpone los datos informáticos al mundo real'’. Existen, además, muchos tipos y niveles de realidad aumentada, la cual cada vez resulta ser más sofisticada gracias al desarrollo tecnológico de los dispositivos móviles y cámaras. Sin embargo, lo que les caracteriza es el hecho de mezclar elementos reales con virtuales, incorporando la tridimensionalidad e introduciendo la interactividad como factor a tiempo real, con la finalidad de generar la sensación de inmersión por parte del espectador, ya sea física o mental.

Además, en cuanto a la realidad aumentada en concreto, sabemos que está siendo la moda en estos últimos meses, sobre todo a raíz del lanzamiento de juegos para los dispositivos móviles que tanto revuelo han estado causando1. Del mismo modo, también podría resultar interesante causar el mismo interés en el ámbito artístico, con algún sistema de realidad aumentada que nos permitiese, de forma lúdica, salir de nuestras casas para conocer más y mejor la Historia del Arte de nuestra ciudad.

En el caso de Málaga, ésta no se queda atrás en el desarrollo virtual y tecnológico con respecto al resto de ciudades españolas. La conectividad a Internet es constante y bastante efectiva tanto dentro como fuera de los hogares malagueños, y todo ello afecta al modo en el que contemplamos y nos acercamos a la ciudad, en donde, al igual que en gran parte del mundo, ven antes una cámara que unos ojos, ejerciendo a veces de barrera y otras de intermediario entre ambos.

Sin embargo, la introducción de la realidad aumentada apenas se ha dejado notar en nuestra ciudad, al contar con escasas aplicaciones relacionadas con ella. No obstante, una de estas es la

\footnotetext{
${ }^{1}$ Uno de estos ejemplos que están revolucionando actualmente el panorama internacional de la realidad aumentada ha sido el juego Pokémon Go, sacado a la luz por la empresa Niantic el pasado 6 de julio y el cual ha hecho que, en cuestión de días, miles de usuarios, de todas las edades y variedades, recorran la ciudad en busca de estos pokémon que se le aparecen a través de la realidad aumentada en el lugar en el que se encuentra en ese momento según el GPS que el dispositivo lleva incorporado.
} 
llevada a cabo por la EMT de Málaga a través de la iniciativa realizada en colaboración con la Diputación de Málaga y Orange, en la cual se sirven de la realidad aumentada para facilitar a los usuarios el conocimiento y localización de los autobuses que circulan por la ciudad en todo momento. Otra de las aplicaciones, nacida en 2012, es la denominada 'Costa del Sol Málaga'2, también realizada por la Diputación de Málaga y Orange a través de tecnología de Mobincube. Tal y como explican en la propia aplicación de móvil, "han colaborado con ella los Servicios de Turismo y Promoción del Territorio, Tecnologías de la Información, e Información Territorial’’ enfocada al turismo, centrada tanto al casco histórico como al resto de municipios (101 municipios en total) que la constituyen y rodean. En ella se introduce información de todo tipo, desde imágenes, vídeos y textos explicativos de monumentos, hasta mapas, clima, establecimientos singulares, seguridad, estaciones de servicio, etc. Sin embargo, a día de hoy, sólo contempla el uso de la realidad aumentada como forma de localizar al usuario en cada momento. Se constituye pues como una app móvil, bastante completa y eficaz, si bien enfocada sobre todo al turista.

Por otro lado, la implantación de códigos QR en los museos, escaparates y calles de nuestras ciudades parecen invadir la capital, al ser una herramienta bastante sencilla y práctica. Por tanto, en esta parte del trabajo queremos potenciar al máximo todos los recursos que ofrecen los QR para elaborar, a largo plazo y aunándolos con el uso de la realidad aumentada, un posible proyecto práctico en nuestra ciudad. Del mismo modo, debemos ser conscientes de que estamos ante una nueva fase de adaptación de estas nuevas herramientas a los museos, por lo que de momento son pocos los que han implantado la realidad aumentada en sus espacios, y menos aún los locales. Por tanto, también intentaremos mostrar la aplicabilidad de dicha herramienta en obras pictóricas de uno de los museos de Málaga.

Ninguno de estos proyectos se encuentra finalizado, debido a que se requiere más tiempo para lograr un estudio más profundo y una participación colectiva realizada desde diferentes áreas profesionales, tanto de la humanística como de la tecnológica, para poderse llevar a cabo. Sin embargo, lo que se pretende con el planteamiento de dichos proyectos y con esta parte del trabajo es sobre todo demostrar una vez más que el historiador del arte es capaz de emprender y crear, no sólo limitarse a la recopilación de información, con la finalidad de obtener, finalmente, una investigación que realmente aporte algo nuevo y práctico a este campo de la Historia del Arte. No nos

${ }^{2}$ ttps://www.youtube.com/watch?feature=player_detailpage\&v=yxXx7QxXOMY (fecha de consulta: 26-072016). 
conformaremos sólo con investigar, sino que trataremos de dar respuesta a estos nuevos paradigmas que se están desarrollando e intentando abrir nuevas líneas de investigación teórico-práctica.

\section{Ejemplo práctico de Realidad Aumentada aplicada a la obra de Jorge Rando}

El siguiente proyecto surgió durante mi período de prácticas del Máster en Desarrollos Sociales de la Cultura Artística realizadas en el Museo Jorge Rando, cuando, hablando con la directora del mismo, Vanesa Díez, le comenté la idea de dicho trabajo y su relación con la realidad aumentada. Debido a la flexibilidad y el afán por emprender por parte del museo y viendo la relevancia que podrían llegar a tener el uso de las nuevas tecnologías en los mismos, la directora me propuso la idea de plantear un ejemplo práctico y novedoso que diferenciase a dicho museo del resto de instituciones museísticas malagueñas. Aunque aún está en proceso de implantación por parte del personal informático con el que contarán a partir de octubre, la idea se dejó planteada antes de finalizar las prácticas.

Barajando varias opciones y teniendo presente varios sistemas de realidad aumentada, la opción final elegida fue el empleo del sistema Layar. La principal razón es que dicha aplicación ofrece la posibilidad de utilizar la realidad aumentada de forma no muy compleja y a través de nuestros dispositivos móviles y tablets, funcionando mediante la superposición de capas. Sin embargo, la caducidad con la que cuenta dicho sistema, si no contratamos la opción de pago, así como el inconveniente de no contar con opciones personalizadas y acordes a la filosofía y discurso del museo, nos hizo pensar en la posible elaboración de un software propio a través del cual se procediera a la implantación de realidad aumentada y que fuera algo propio del museoz. De este modo, en el proyecto se propone la aplicación de la realidad aumentada sobre obras pertenecientes a la colección del museo, la cual recoge pinturas neoexpresionistas del artista malagueño Jorge Rando. Para la elaboración del mismo seguimos las siguientes pautas:

A través de dicha aplicación, cuya descarga se realiza en el dispositivo móvil por un lado y en el ordenador por el otro, escogemos una foto de una obra del artista. Sobre ella, en el ordenador y a través de la misma aplicación, tenemos la posibilidad de insertar imágenes en una de las capas. Una de las opciones a escoger es la de introducir imágenes de obras que pertenecen al mismo ciclo de dicha pintura, así como la introducción de imágenes que muestren la obra desde diferentes perspectivas. En nuestro caso se ha escogido una obra perteneciente al ciclo pictórico llamado

\footnotetext{
$\overline{3}$ Con este hecho se lograría una mayor libertad y novedad en el campo de estas nuevas tecnologías, si bien dicho procedimiento debe ser llevado a cabo por el personal informático al que nos referíamos antes.
} 
'Ciclistas', sobre la cual insertamos imágenes correspondientes al mismo ciclo4 [1 y 2].

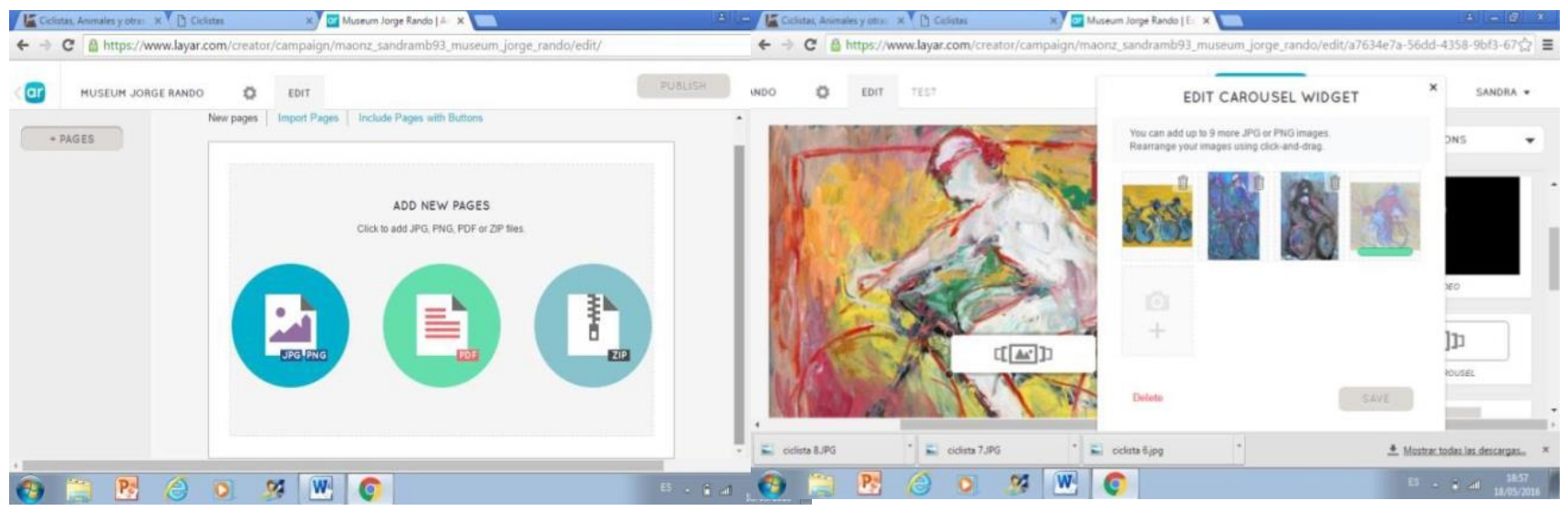

[Fig. 1 y 2] Implantación de realidad aumentada sobre una de las obras de Jorge Rando perteneciente a su ciclo pictórico 'Ciclistas'.

Otra de las posibilidades que también nos ofrece la aplicación es el poder añadir el enlace de la web del museo, pinchando en "Website" e introduciendo la dirección, así como la introducción del enlace a un vídeo, en este caso, aprovechando los vídeos del montaje de las obras y siguiendo el mismo procedimiento [3 y 4 ].

Al colocar el dispositivo móvil sobre la propia obra del ciclista, nos aparecería sobre la pantalla del mismo una serie de capas que nos permitirían conocer más a fondo los detalles de cada una de ellas [5], bajo un sistema simple y barato, a la vez que diferente e innovador con respecto al resto de museos. Dicho procedimiento se realizaría en cada una de las obras colocadas en el museo, quedando luego almacenadas en la propia web del mismo en el momento en el que éstas fuesen desmontadas.

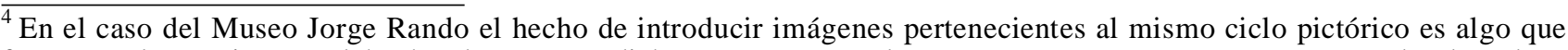
favorece al usuario por el hecho de que, en dicho museo, normalmente no se encuentran expuestas todas las obras pertenecientes a un ciclo pictórico del artista, por lo que el visitante no tiene oportunidad de verlas todas a la vez in situ, de forma que el uso de la realidad aumentada sería algo que completaría la visión y visita del usuario. Así, dicho proceso se repetiría en exposiciones como la que actualmente se encuentra allí, 'Ciclistas, animales y otras cosas'.
} 


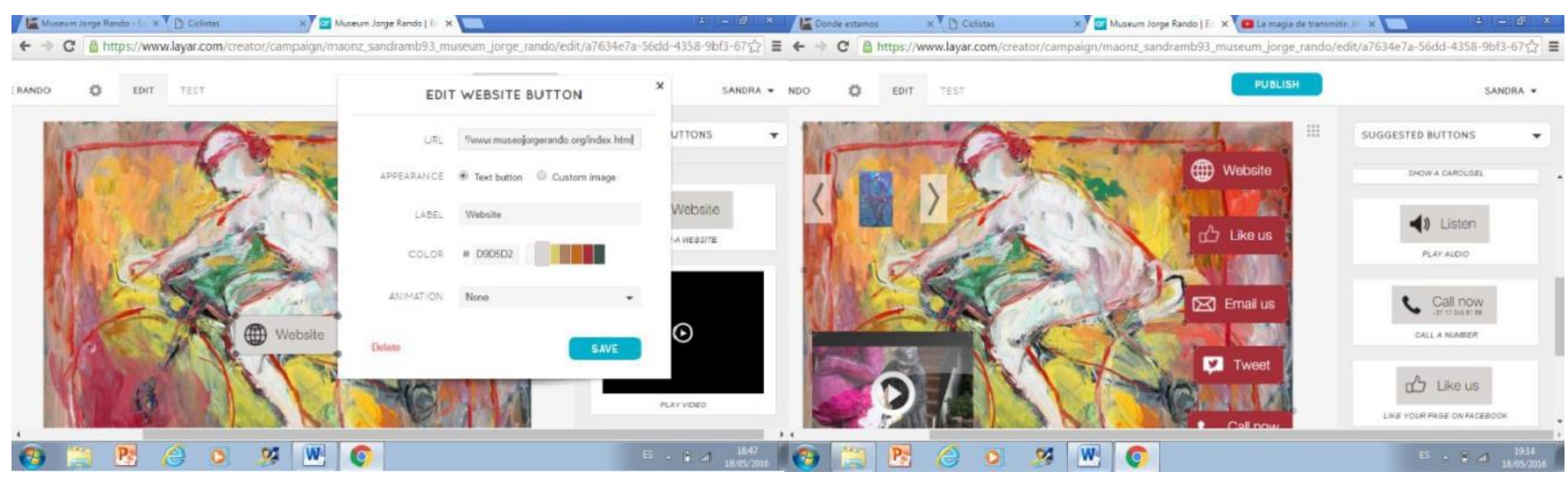

[Fig. 3 y 4] Implantación de realidad aumentada sobre una de las obras de Jorge Rando perteneciente a su ciclo pictórico 'Ciclistas'.

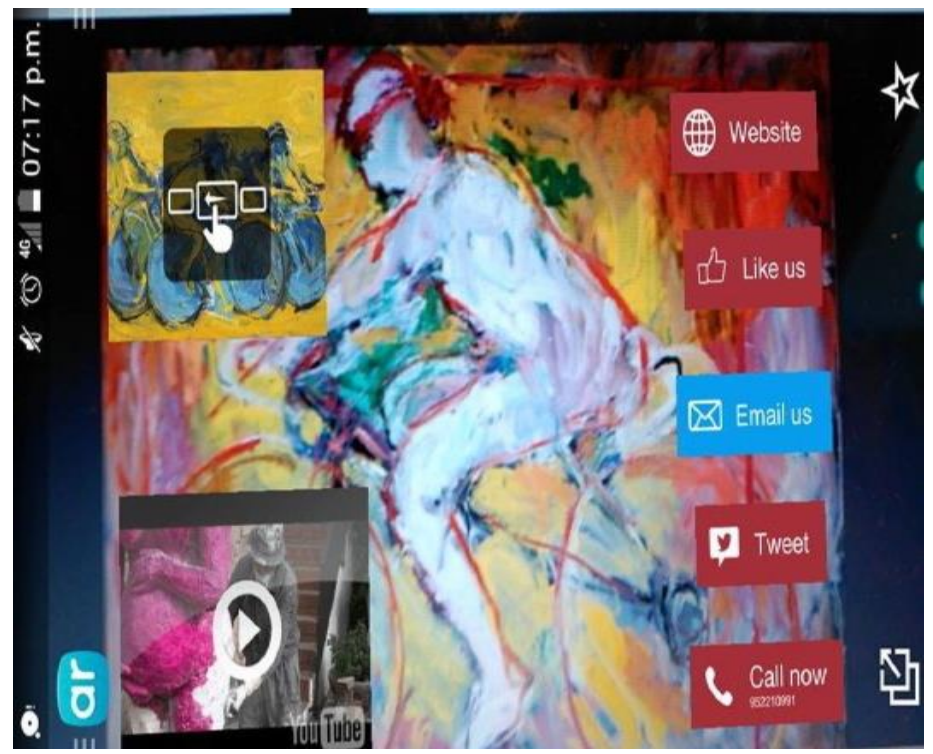

[Fig 5]. Resultado del proceso de aplicación de realidad aumentada a la obra del ciclo pictórico 'Ciclistas', del pintor Jorge Rando

Con este proyecto nos situaríamos a la vanguardia de los museos malagueños en el ámbito de la realidad aumentada, ya que hasta el día de hoy no encontramos nada similar en nuestro entorno museístico. A ello hay que sumarle el hecho de que el museo se encuentra en uno de los barrios que durante años ha estado algo degradado tanto social como culturalmente y que, sin embargo, se sitúan justo en los alrededores del centro de la capital, en concreto hablamos del barrio de la Cruz del Molinillo, con lo que sería otra forma de reubicar y situar al museo en la red. De esta manera, el visitante tendría la oportunidad de interactuar con las obras del artista, a la vez que los más pequeños también se verían favorecidos por estas técnicas tan entretenidas para ellos, pudiendo ser aprovechadas, además, para los talleres infantiles que allí se realizan de forma semanal. 


\section{Proyecto QRutas Málaga}

Uno de los principales intereses a la hora de llevar a cabo esta investigación ha sido realizar recorridos virtuales sobre la ciudad de Málaga, a través de los códigos QR y la realidad aumentada mediante capas. Este interés está motivado por la riqueza patrimonial, tanto histórico-artística como gastronómica, musical, paisajística, etc., que caracteriza a nuestra ciudad, así como al posible interés que pudiera suscitar debido a su carácter novedoso y, a la vez, relacionado con el desarrollo virtual y tecnológico.

El proyecto, si bien se encuentra en su fase más inicial, al no contar ni con los medios ni con el personal suficiente, surgía como idea de complementar, in situ, la visita a todo aquel que quisiera conocer más sobre todo lo concerniente a nuestra ciudad. La idea, pues, comenzaría por abarcar, a priori, el casco histórico malagueño, enfocándolo desde un punto de vista histórico-artístico en el que se mostrasen todos aquellos lugares de interés que, desde los más antiguos vestigios romanos hasta llegar al más novedoso Centro Pompidou, dejasen constancia de todo aquello que caracterizase a los diferentes períodos por los que ha pasado nuestra milenaria ciudad.

Para ello se procedió, a modo de simulacro, a la creación de una página web denominada 'QRutas Málaga'5, a través del software gratuito wordpress y en cuya portada se explica la finalidad de dicho proyecto:

Esta página tiene la finalidad de llevarte por las calles de Málaga, con la intención de poner al alcance de tu mano toda la información posible acerca de la misma. Paseando por ella encontrarás códigos $Q R$ que te remitirán directamente a este portal, desde el cual podrás, también, acceder a nuestro Instagram, desde donde obtendrás una panorámica visual diferenciada por los hastags según el período histórico-artístico ante el que nos encontremos: Málaga Romana, Málaga Islámica, Málaga Renacentista, Málaga Barroca, Málaga del XIX y Málaga del XX y XXI.

Al igual que en el proyecto anterior del Museo Jorge Rando, a través de QRutas Málaga lo que se pretende hacer es diseñar un ejemplo que mezcle realidad con virtualidad, con la idea de desarrollar el resto de información y códigos QR e insertarlos en la página web en un futuro. A

5 Para visitar la página web creada para 'QRutas Málaga', clicar en el siguiente enlace: https://rutasmalagacapital.wordpress.com/ 
través de un código QR que realizamos mediante Generador QR-Code60 [6], el usuario tiene la posibilidad de colocar su dispositivo móvil sobre el mismo para que le lleve a la página realizada para este proyecto, denominada 'Rutas Málaga Capital', a través de cuyo código se accede a la información, en este caso, acerca de la Málaga Romana [7].

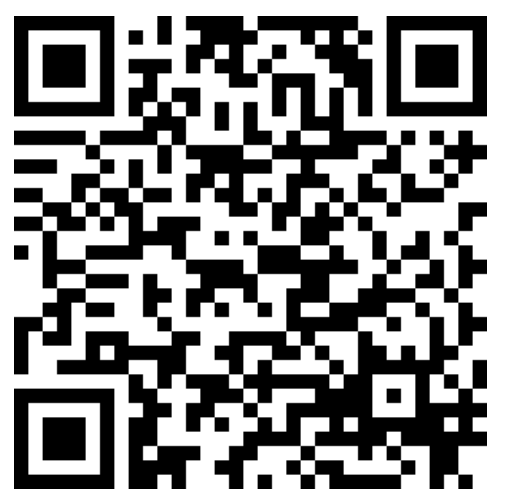

[Fig. 6] Código QR generado para el proyecto QRutas Málaga, el cual remite al usuario a la página web del mismo.

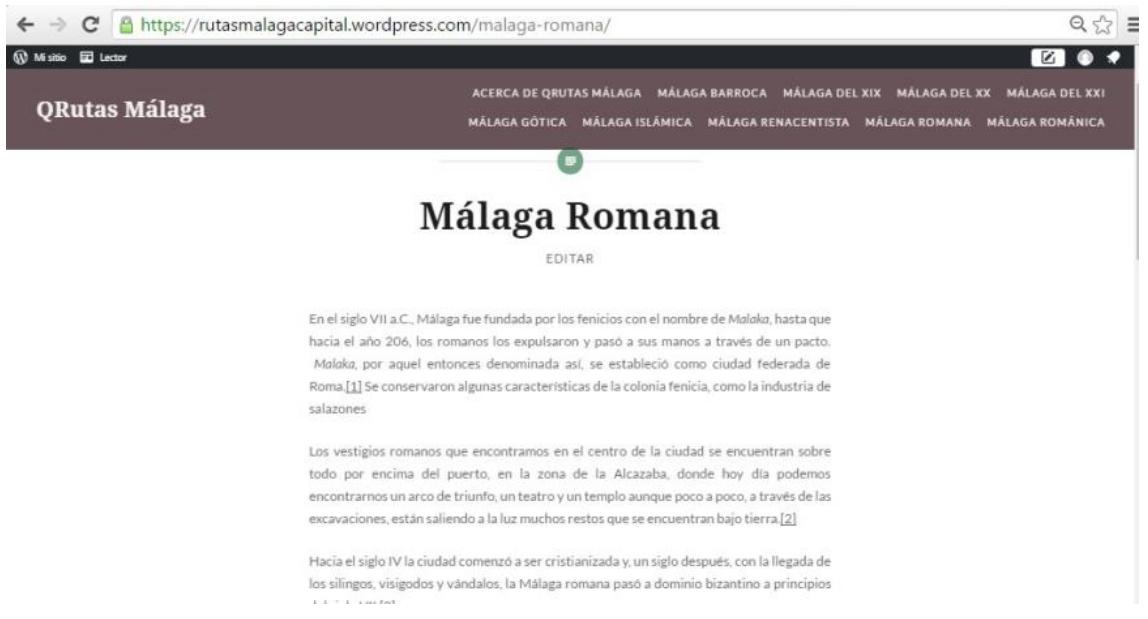

[Fig. 7] Página web 'Rutas Málaga Capital': https://rutasmalagacapital.wordpress.com/malaga-romana/

Para llevarlo a cabo, uno de los modelos que han ayudado a su planteamiento ha sido la Guía histórico-artística de Málaga, dirigida por Rosario Camacho, si bien, al ser del año 1980 y contando con la última edición en el 2006, no contempla ninguno de los acontecimientos, edificios o museos surgidos a partir de entonces. La idea, por tanto, es realizar una especie de reactualización tanto en forma como en contenido, pero también en la manera en la que se comunica este patrimonio y el modo en el que la sociedad se acerca al mismo. Con este hecho se hace necesario el añadido del 
apartado de 'Málaga del XXI', el cual resultaría ser nuestro punto más fuerte y distintivo, al estar basado en la contemporaneidad y, a su vez, requerir de actualización constante. En cuanto a la utilidad del proyecto, éste permitiría a cualquier visitante o ciudadano de a pie conocer de forma inmediata la historia del edificio, plaza o institución ante la que se encuentra con su propio dispositivo móvil como único medio necesario (a diferencia del ejemplo anterior, pensado para el uso de tablets, las cuales serían ofrecidas al visitante por parte del propio museo).

Este mismo proceso, basado en códigos QR se podría complementar con la aplicación de realidad aumentada (de nuevo, mediante la aplicación Layar) sobre los edificios de la ciudad, mediante la cual, a través de las capas superpuestas, por ejemplo, sobre el Teatro Romano [8 y 9], el usuario tuviera la oportunidad, además de visitar nuestra página, de ver vídeos explicativos, información de contacto, imágenes del edificio de diferentes épocas, etc., tal y como se ha realizado para el proyecto anterior. El resultado que obtendríamos al disponer nuestro dispositivo móvil sobre el propio teatro, en este caso, sería un ejemplo de realidad aumentada que nos permitiría acceder por capas a diferentes plataformas tales como la página web, un vídeo explicativo, así como a fotografías antiguas, aéreas y actuales [10].

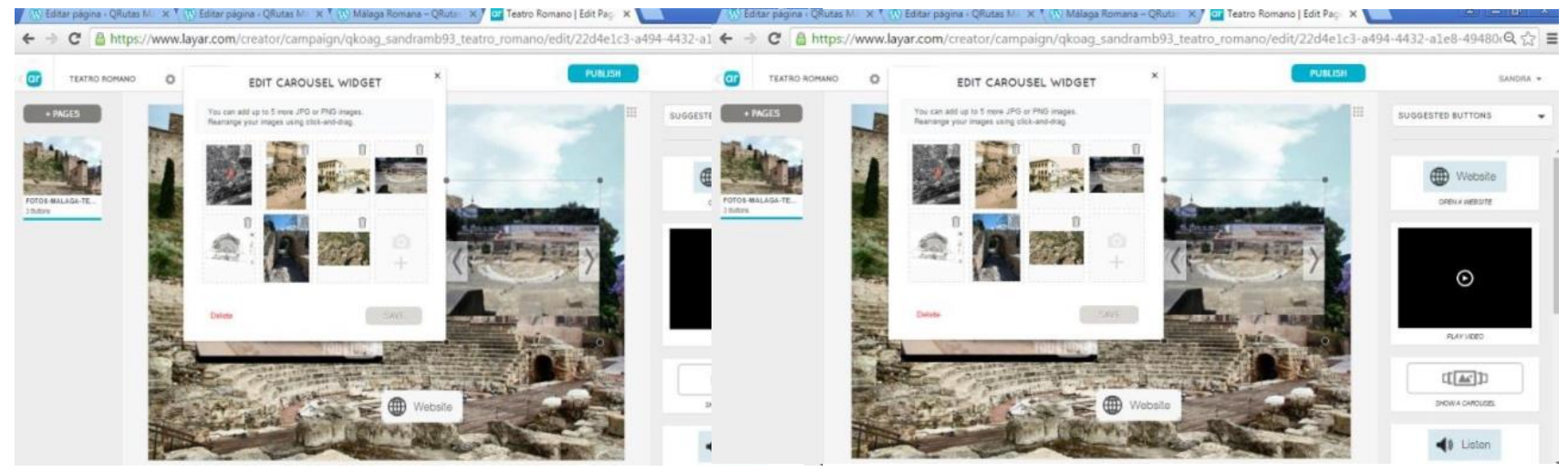

[Fig. 8 y 9] Proceso de elaboración de realidad aumentada por capas mediante Layar para el proyecto 'QRutas Málaga'. 


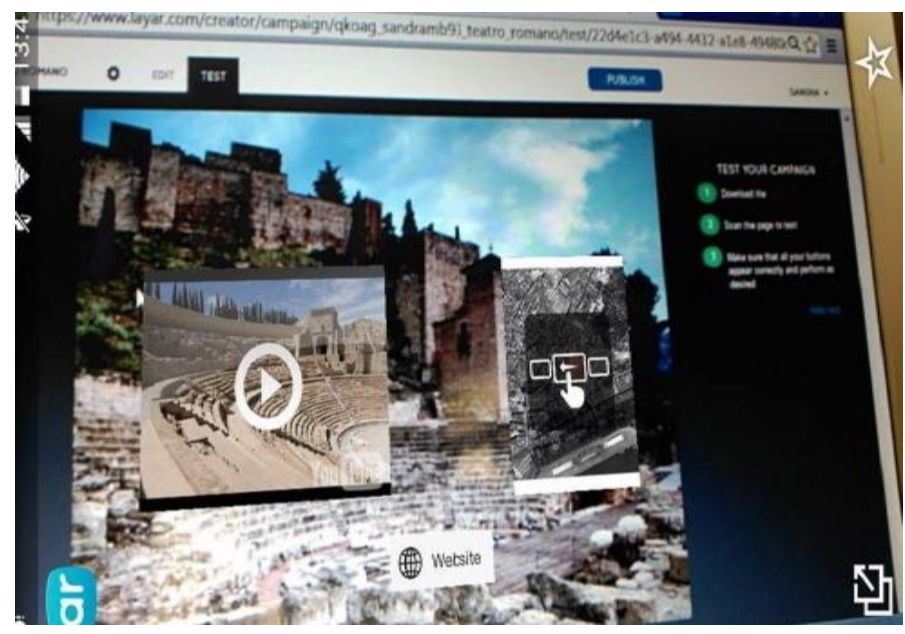

[Fig. 10]. Resultado del proceso de aplicación de realidad aumentada al Teatro Romano de Málaga.

Otro valor añadido con el que contaría este proyecto sería el poder permitir que, al realizar los recorridos por la ciudad, las propias rutas incrementasen, además, la interactividad con el espectador, al permitirle compartir las propias imágenes del lugar que está visitando a través la web 2.0, esto es, mediante redes sociales tales como una cuenta oficial de Instagram. Esto, que a priori pudiera parecer algo irrelevante, a la larga no sólo incrementaría la interactividad con el usuario, sino que además obtendríamos como resultado un corpus fotográfico bastante completo de todos los rincones

la ciudad, en donde se haría totalmente partícipe al propio usuario, algo que tanto está de moda ahora en nuestra ciudad y sociedad.

Tras este planteamiento, cabe decir que no sabemos tampoco si dicho proyecto podrá llevarse a cabo en un futuro, sin embargo, desde un modo local y basado en un modelo que integra el campo histórico-artístico, el proyecto QRutas Málaga también está pensado para ampliar su difusión a entornos como el gastronómico o el musical, incluso a otros pueblos de la provincia, etc., con idea de expandirse y dejar registrada la gran riqueza cultural y patrimonial que caracteriza a la ciudad de Málaga.

A diferencia, por tanto, de la ya comentada app 'Costa del Sol Málaga', nuestro proyecto pretende ir más allá en el contenido, al enfocarlo más a la Historia del Arte y no tanto al turismo, es decir, constituir un corpus basado en las diferentes rutas pertenecientes a Málaga, distanciadas en el tiempo según cada época histórico-artística pero unidas en el mismo espacio. Además, el proyecto estaría diseñado para funcionar mediante el geoposicionamiento (lo interesante es ir descubriendo los rincones conforme el visitante recorre los rincones de la ciudad), y esto es algo que esta app no incluye. 
No se trataría, por tanto, únicamente de colocar la información en la web, sino de hacerla visualmente más amena. Es decir, para ello se haría uso de la realidad aumentada, pero no únicamente como forma de georeferenciar al usuario, sino, sobre todo, como forma de enseñarle, únicamente in situ y no a través de una app móvil con la que se pueda acceder a la información en todo momento, todo aquello que quisiera saber en relación con lo que se encuentra, en ese momento, ante sus ojos (información, anteriores reconstrucciones o restauraciones, fotografías antiguas del lugar, vídeos explicativos, además del contacto y otra serie de opciones). De este modo se le obligaría al visitante a pasear y a conocer al mismo tiempo, así como a interactuar con su entorno.

Por tanto, si bien QRutas Málaga nace como proyecto en estas páginas, la idea es darle un enfoque aún más verídico para poder llevarlo a la práctica y que se pueda convertir, en un futuro no muy lejano, en una empresa cultural digna de contar con un personal cualificado en las diversas áreas, así como de crear un discurso actualizado, dinámico y original de la propia ciudad de Málaga.

\section{Conclusiones}

Si bien la calidad técnica de dicha investigación y puesta en práctica aún se ve limitada debido a los medios y al escaso conocimiento informático, sí que hemos podido comprobar que es posible implantar nuevos sistemas o proyectos en nuestro entorno más cercano, desarrollando, entre otras cosas, una página web, generando códigos $\mathrm{QR}$, así como diseñando realidad aumentada para un museo o para el interior de un aula. La realidad aumentada, por tanto, se está constituyendo como uno de los sistemas que están protagonizando un gran desarrollo en el ámbito artístico, ya sea como herramienta para la arqueología o la restauración, o bien para deleite del turista o la construcción lo más completa posible de la Historia del Arte.

Ante el futuro que les augura tanto al arte como a los museos que están emergiendo, si bien resulta en parte imprevisible, sí que podemos decir que el arte rara vez se cierra las puertas que se le abren. Por este hecho, posiblemente, a no muy largo plazo y debido tanto al avance de las tecnologías como al gran atractivo que éstas causan en gran parte del público, las formas de hacer y conocer la Historia del Arte estarán muy unidas con dicha sociedad digital, la cual demandará aún más estas nuevas metodologías. Deberemos adaptarnos a los cambios bajo el lema de 'renovarse o morir', pero sin caer en la alienación que puede generar el uso de las tecnologías y que puede 
afectar de forma negativa al individuo y la sociedad, así como a la forma de ver y concebir la Historia del Arte. Como ejemplo de ello y como conclusión encontramos que estos ejemplos pretenden ir más allá de lo que se conoce hasta ahora en el campo de la práctica artística, estableciendo nuevas propuestas que den pie a nuevas formas de transmitir y conocer el mundo histórico-artístico.

\section{Referencias bibliográficas}

ADELL SEGURA, Jordi, y CASTAÑEDA QUINTERO, Linda (2012), “Tecnologías emergentes ¿pedagogías emergentes?’, en HERNÁNDEZ ORTEGA et al (coord.), Tendencias emergentes en educación con TIC. Espiral: Barcelona, pp. 13-32.

BELLIDO GANT, María Luisa (2008), “'Los fundamentos del Medio Digital’, Difusión del Patrimonio Cultural y Nuevas Tecnologías. Universidad Internacional de Andalucía (UIA): Córdoba, pp. 36-53.

BELLIDO GANT, María Luisa y RUIZ TORRES, David. “Museos de nueva generación: la pantalla como acceso", Recuperado de: http://www.ugr.es/ mbellido/PDF/012.pdf (fecha de consulta: 10-07-2016).

BONNIN, Juan y CABEZAS, Sergio G. La Realidad Aumentada y las Pizarras Digitales Interactivas. Recuperado de: https:/www.uam.es/gruposinv/dim/assets/bonin2013.pdf (fecha de consulta: 13-07-2016).

BREA, José Luis (2002/2009). La era postmedia. Acción comunicativa, prácticas (post) artísticas y dispositivos neomediales. Centro de Arte de Salamanca (CASA): Salamanca.

CÁCERES-PÉFAUR, Beatriz, "Cultura visual y educación. Nuevos desafíos / nuevos paradigmas". Anuario del Doctorado en Educación: Pensar la Educación, nº 4, 2010, pp. 75-99.

CASTILLO RUIZ, José (2008), “Patrimonio histórico y nuevas tecnologías. El Observatorio del Patrimonio Histórico (OPHE)’, en BELLIDO GANT, María Luisa (dir.), Difusión del Patrimonio Cultural y Nuevas Tecnologías. Universidad Internacional de Andalucía (UIA): Córdoba, pp.12-35.

CÓZAR GUTIÉRREZ, Ramón (2015), “Tecnologías emergentes para la enseñanza de las Ciencias Sociales. Una experiencia con el uso de Realidad Aumentada en la formación inicial de maestros", en Digital Education Review, no 27, junio, pp. 138-153. 
FOMBONA CADAVIECO, Javier y VÁZQUEZ-CANO, Esteban (en prensa), "Posibilidades de utilización de la Geolocalización y Realidad Aumentada en el ámbito educativo". Educación $X X 1$.

FORÉS MIRAVALLES, Anna (2012), “E-mociones. Sin emoción no hay educación’”, en HERNÁNDEZ ORTEGA et al (coord.), Tendencias emergentes en educación con TIC. Espiral: Barcelona, pp. 51-66.

HURTADO MENDIETA, Enrique (2013), “Arte y Máquinas”, Arte y Políticas de identidad, vol. 9., diciembre, pp. 103-112. 47

GALLEGO DELGADO, Roberto, SAURA PARRA, Nerea y NÚÑEZ TRUJILLO, Pedro Miguel (2012), “AR-Learning: libro interactivo basado en realidad aumentada con aplicación a la enseñanza'. Recuperado de: file:///C:/Users/Usuario/Downloads/DialnetARLearningLibroInteractivoBasadoEnRealidadAumentad-5385923\%20(1).pdf (fecha de consulta: 13-07-2016).

GONZÁLEZ, Marisa, 'Arte y Tecnología'’. Recuperado de:

http://www.uv.es/fores/contrastes/seis/gonzalez_marisa.html (fecha de consulta: 10-07-2016).

GUBERN, Roman (1996). Del bisonte a la realidad virtual. La escena y el laberinto, Anagrama: Barcelona.

MORENO VERA, Juan Ramón, y LÓPEZ VERA, Igor, "Proyecto de investigación educativa: la Historia del arte a través de códigos $Q R$ '. Recuperado de: http://web.ua.es/es/ice/jornadasredes/documentos/2013-comunicaciones-orales/332910.pdf (fecha de consulta: 03-07-2016).

MUNÁRRIZ ORTIZ, Jaime (2013). “Arte geo-localizado”, en Arte y Sociedad (ARSI), vol. 4, abril, pp.1-18. 